\title{
Synthesis of N-Alkyl-2-thiomethyl Benzimidazoles: A Green Approach
}

\author{
S. Srinivas Rao, Ch. Venkata Ramana Reddy, and P. K. Dubey \\ Department of Chemistry, College of Engineering, Jawaharlal Nehru Technological University Hyderabad, \\ Kukatpally, Hyderabad 500 085, India
}

Correspondence should be addressed to S. Srinivas Rao; seenu604@gmail.com

Received 19 November 2013; Revised 26 January 2014; Accepted 14 February 2014; Published 17 March 2014

Academic Editor: William Ogilvie

Copyright (c) 2014 S. Srinivas Rao et al. This is an open access article distributed under the Creative Commons Attribution License, which permits unrestricted use, distribution, and reproduction in any medium, provided the original work is properly cited.

A green approach for the synthesis of $\mathrm{N}$-alkyl-2-thiomethyl benzimidazoles $2\left(\mathrm{R}=\mathrm{CH}_{3}, \mathrm{C}_{2} \mathrm{H}_{5}, \mathrm{CH}_{2} \mathrm{Ph}\right)$ under different conditions has been developed from $\mathrm{N}$-alkyl-2-chloromethyl benzimidazole (i.e., $\mathrm{CH}_{3}, \mathrm{C}_{2} \mathrm{H}_{5}, \mathrm{CH}_{2} \mathrm{Ph}$ ) 1 by reaction with thiourea by physical grinding, or by using green solvents like ethanol and PEG-600, or by using microwave irradiation technique.

\section{Introduction}

Benzimidazoles are very useful intermediates/subunits for the development of molecules of pharmaceutical or biological interest $[1,2]$. Benzimidazoles are an important class of bioactive molecules in the field of drugs and pharmaceuticals [3-7].

$\mathrm{N}$-Methyl-o-phenylenediamine on treatment with thioacetic acid in $\mathrm{HCl}$ under reflux gave N-methyl-2-thiomethyl benzimidazole that was reported [8] by Casella et al. Rall et al. described [9] that N-methyl o-Phenylenediamine with S-benzyl thioacetic acid in aq. $\mathrm{HCl}$ under reflux gave N-benzyl-2-benzylthio methylbenzimidazole. Kato et al. reported [10] that 2-((methylthio)methyl)-1H-benzimidazole was prepared on treatment of S-methylthio acetic acid with o-phenylenediamine in aq. $\mathrm{HCl}$ under reflux for $16 \mathrm{hr}$. Reaction of S-methylthio methylbenzimidazole on treatment with methyl iodide in presence of sodium methoxide gave $\mathrm{N}$-methyl-S-methylthio methylbenzimidazole that was reported by Haugwitz et al. [11]. Zubenko et al. reported [12] that $\mathrm{N}$-methyl-2-chloromethyl benzimidazole was reacted with thiomethane in ethanol in $\mathrm{NaOMe}$ and gave N-methyl-2-methylthio methylbenzimidazole. Rao et al. [13] reported that $\mathrm{N}$-alkyl-2-chlorobenzimidazole was treated with thiourea green conditions and gave N-alkyl-2-thiomethyl benzimidazole in good yields. In continuation of our earlier studies [14], we now wish to report a green syntheses of N-alkyl-2-thiomethylbenzimidazoles.

\section{Results and Discussion}

Reaction of 1a-c, that is, $\mathrm{N}$-alkyl-2-chloromethyl benzimidazole [8] $\left(\mathrm{R}=\mathrm{CH}_{3}, \mathrm{C}_{2} \mathrm{H}_{5}\right.$, or $\left.\mathrm{PhCH}_{2}\right)$, independently, each with thiourea by a simple physical grinding of the reaction mixture in a mortar with a pestle, under solventfree conditions, for $10-15 \mathrm{~min}$ at RT, followed by simple processing, gave respectively (1-methyl-1H-benzimidazol-2yl)methanethiol (2a, i.e., 2, $\mathrm{R}=\mathrm{CH}_{3}$ ), (1-ethyl-1H-benzimidazol-2-yl)methanethiol (2b, i.e., $2, \mathrm{R}=\mathrm{C}_{2} \mathrm{H}_{5}$ ), and (1-benzyl$1 \mathrm{H}$-benzimidazol-2-yl)methanethiol (2c, i.e., $2, \mathrm{R}=\mathrm{CH}_{2} \mathrm{Ph}$ ) in excellent yields, matching the products identically with the ones reported [8] by the literature in all respects (m.p., m.m.p., and co-TLC) (Scheme 1).

The reaction of $\mathbf{1 a}, \mathbf{1 b}$, and $\mathbf{1 c}$, independently, each with thiourea in ethanol under reflux for $3 \mathrm{hr}$, followed by simple processing, gave respectively $\mathbf{2 a}$ (i.e., $\mathbf{2}, \mathrm{R}=\mathrm{CH}_{3}$ ), $\mathbf{2 b}$ (i.e., $\mathbf{2}$, $\mathrm{R}=\mathrm{CH}_{2} \mathrm{CH}_{3}$ ), and $2 \mathrm{c}$ (i.e., $2, \mathrm{R}=\mathrm{CH}_{2} \mathrm{Ph}$ ) identical with the same products obtained above (Scheme 1 ).

The reaction was also carried out in PEG-600 as the green solvent. Thus, heating a mixture of $\mathbf{1 a}, \mathbf{1 b}$, and $\mathbf{1 c}$, independently, each with thiourea in PEG-600 for $3 \mathrm{hr}$ without the use of any added base, followed by simple processing, gave, respectively, 2a (i.e., 2, $\mathrm{R}=\mathrm{CH}_{3}$ ), $\mathbf{2 b}$ (i.e., 2, $\mathrm{R}=\mathrm{CH}_{2} \mathrm{CH}_{3}$ ), and $2 \mathrm{c}$ (i.e., $2, \mathrm{R}=\mathrm{CH}_{2} \mathrm{Ph}$ ) identical with the same products obtained above (Scheme 1).

Compounds $2 \mathbf{a}-\mathbf{c}$ could also be prepared by an alternative, green method. Thus, $\mathbf{1 a}, \mathbf{1 b}$, and $\mathbf{1 c}$, independently, 


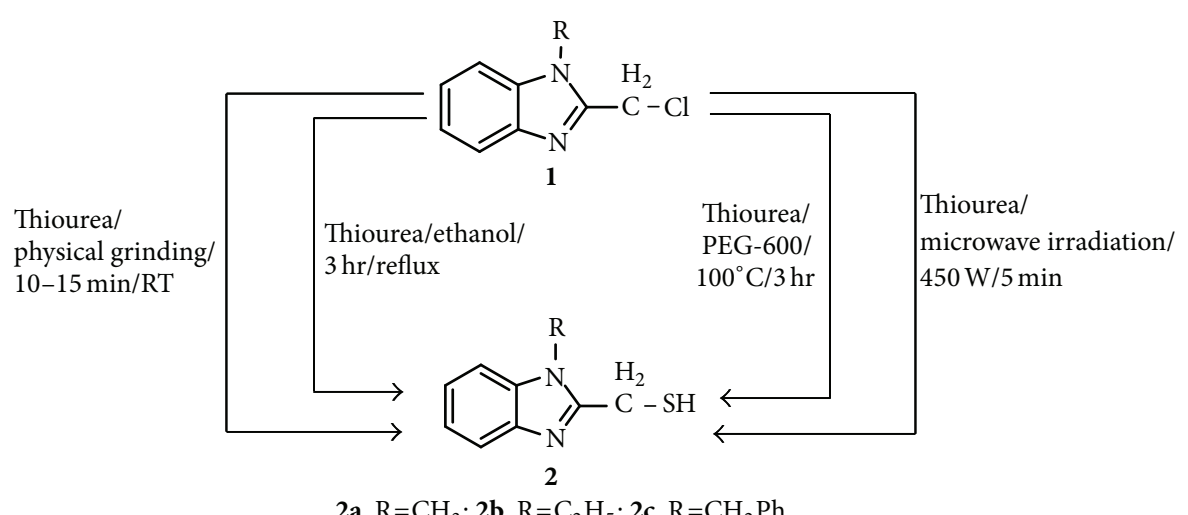

SCHEMe 1: $\mathbf{2} \mathbf{a}, \mathrm{R}=\mathrm{CH}_{3} ; \mathbf{2} \mathbf{b}, \mathrm{R}=\mathrm{C}_{2} \mathrm{H}_{5} ; \mathbf{2} \mathbf{c}, \mathrm{R}=\mathrm{CH}_{2} \mathrm{Ph}$.

each with thiourea under microwave irradiation conditions for $2 \mathrm{~min}$ and subsequent processing, gave respectively $\mathbf{2 a}$ (i.e., 2, $\mathrm{R}=\mathrm{CH}_{3}$ ), $\mathbf{2 b}$ (i.e., $2, \mathrm{R}=\mathrm{CH}_{2} \mathrm{CH}_{3}$ ), and $\mathbf{2 c}$ (i.e., 2, $\mathrm{R}=\mathrm{CH}_{2} \mathrm{Ph}$ ) identical with the products obtained above (Scheme 1).

Thus, the above four methods have different yields with one suffering from relatively poor yields. Among in ethanol and PEG-600, ethanol gives more yields whereas PEG-600 gives lower yields. Due to high molecular weight and viscous nature of PEG-600 ( $135 \mathrm{cp}$ at $\left.25^{\circ} \mathrm{C}\right)$, it may lower reaction rates, reduce product yields, and cause the reaction to be mass-transfer limited. Because of this, three of the four methodologies result in the preparation of the compounds giving high yields whereas PEG-600 gives lower yields. Among these four methodologies, the microwave irradiation is superior to that of three methods because microwave dielectric heating is more energy efficient than classical conductive heat transfer methods.

\section{Experimental Section}

Melting points were determined in open capillaries in sulfuric acid bath and are uncorrected. IR spectra were recorded with Jasca FT-IR 5300. ${ }^{1} \mathrm{H}$ NMR and ${ }^{13} \mathrm{C}$ NMR were recorded in $\mathrm{CDCl}_{3} / \mathrm{DMSO}$ using Varian $400 \mathrm{MHz}$ instrument. Mass spectra were recorded on an Agilent LCMS instrument giving only $\mathrm{M}^{+}$values in $\mathrm{Q}+1$ mode. Thinlayer chromatography (TLC) analyses were carried out on glass plates coated with silica gel GF-254 and visualization was achieved using iodine vapors or UV lamp. Experiments under microwave irradiation were carried out by using the commercially available CEM Discover Microwave Reactor.

\subsection{Preparation of 2 from 1}

3.1.1. Physical Grinding Method. A mixture of $\mathbf{1 a}-\mathbf{c}(10 \mathrm{mM})$ and thiourea $(0.76 \mathrm{~g}, 10 \mathrm{mM})$ was ground for about $10-15 \mathrm{~min}$ in a mortar with a pestle at RT to obtain a homogeneous mixture. The completion of the reaction was monitored by TLC on silica gel-G plates using authentic samples of the starting material and the target compounds as references. The mixture was then treated with ice-cold water $(\approx 30-40 \mathrm{~mL})$. The separated solid was filtered, washed with water $(2 \times$ $10 \mathrm{~mL}$ ), and dried to obtain crude $\mathbf{2 a}-\mathbf{c}$. Yields are shown in Table 1. Recrystallization of the crude product from ethyl acetate gave pure $\mathbf{2 a}-\mathbf{c}$. IR, ${ }^{1} \mathrm{H}$ NMR, and LC-MS spectra for the compounds $\mathbf{2} \mathbf{a}-\mathbf{c}$ were found to be in agreement with the structures assigned to them.

3.1.2. In Ethanol. A mixture of $1 \mathbf{a}-\mathbf{c}(10 \mathrm{mM})$ and thiourea $(0.76 \mathrm{~g}, 10 \mathrm{mM})$ in ethanol was refluxed on water bath for $3 \mathrm{hr}$. The progress of the reaction was monitored on TLC for the disappearance of $\mathbf{1}$. After the completion of the reaction $(\approx 3 \mathrm{hr})$, the excess ethanol was rotary evaporated and the residue poured into ice-cold water $(30 \mathrm{~mL})$. The separated solid was filtered, washed with water $(2 \times 10 \mathrm{~mL})$, and dried. For yields, please see Table 1 . The crude products were purified by recrystallization from ethyl acetate to obtain pure $\mathbf{2 a}-\mathbf{c}$, identical with the same products obtained above.

3.1.3. In $P E G-600$. A mixture of $\mathbf{1 a}-\mathbf{c}(10 \mathrm{mM})$, thiourea $(0.76 \mathrm{~g}, 10 \mathrm{mM})$, and PEG-600 $(20 \mathrm{~mL})$ was heated on a steam-bath at $100^{\circ} \mathrm{C}$ for $3 \mathrm{hr}$. At the end of this period, the mixture was cooled to RT and poured into ice-cold water $(\approx 50 \mathrm{~mL})$. The separated solid was filtered, washed with water $(2 \times 10 \mathrm{~mL})$, and dried. Yields are shown in Table 1 . The crude product was purified by recrystallization from ethyl acetate to obtain pure $\mathbf{2 a}-\mathbf{c}$, identical with the same products obtained above.

3.1.4. Under Microwave Condition. A mixture of $\mathbf{l a - c}$ $(10 \mathrm{mM})$ and thiourea $(0.76 \mathrm{~g}, 10 \mathrm{mM})$ was taken in a $10 \mathrm{~mL}$ CEM-reaction tube sealed by rubber stopper and subjected to microwave irradiation for $2 \mathrm{~min}$ at $130^{\circ} \mathrm{C}$ in a commercial microwave reactor. After that, the tube was cooled and the completion of reaction was checked by TLC. Then, the reaction mixture was poured into ice-cold water $(50 \mathrm{~mL})$. The separated solid was filtered, washed with water $(2 \times 10 \mathrm{~mL})$, and dried. Yields are shown in Table 1. The crude products 


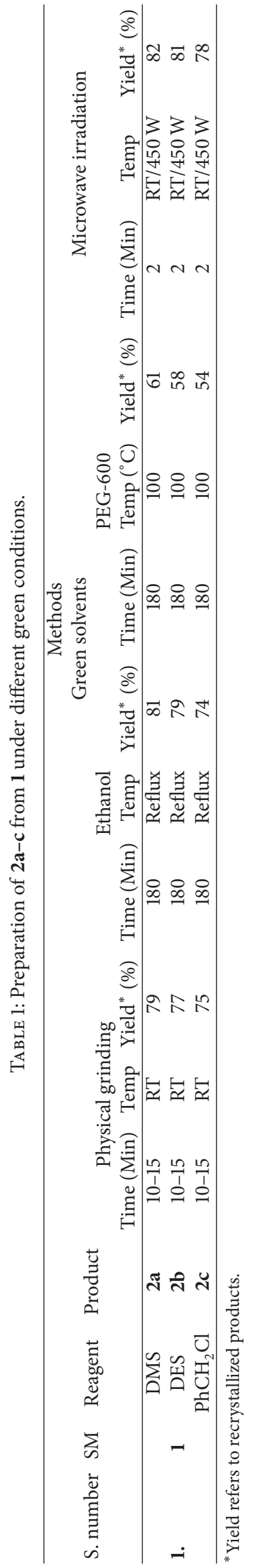


were purified by recrystallization from ethyl acetate to obtain pure $\mathbf{2 a}-\mathbf{c}$, identical with the same products obtained above.

\subsection{Characterization Data}

(1-Methyl-1H-benzimidazol-2-yl)methanethiol, 2a. M.P. 141$45^{\circ} \mathrm{C}$ (Lit. ${ }^{\text {(7) }}$ m.p. $139-43^{\circ} \mathrm{C}$ ); IR (KBr): $2418-2396 \mathrm{~cm}^{-1}$ (-SH); ${ }^{1} \mathrm{H}$ NMR (400 MHz, DMSO-d 6 /TMS): $\delta 3.66$ (s, 3H, $-\mathrm{NCH}_{3}$ ), 9.24 (s, $1 \mathrm{H},-\mathrm{SH}$ ), and 7.35-8.47 (complex, m, and $4 \mathrm{H}$ aryl protons); ${ }^{13} \mathrm{C}$ NMR: $\delta 172.2,138.8,132.5,125.4,118.4$, and $25.9 \mathrm{ppm}$; MS (CI): $\mathrm{m} / \mathrm{z} 179\left[\mathrm{M}^{\circ+}+1\right]$.

(1-Ethyl-1H-benzimidazol-2-yl)methanethiol, 2b. M.P. 118$22^{\circ} \mathrm{C}$ (Lit. ${ }^{(7)}$ m.p. $120-24^{\circ} \mathrm{C}$ ); IR (KBr): $2485-2312 \mathrm{~cm}^{-1}$ $(-\mathrm{SH}) ;{ }^{1} \mathrm{H}$ NMR (400 MHz, DMSO-d 6 /TMS): $\delta 2.75$ (q, $2 \mathrm{H}$, and $-\mathrm{NCH}_{2}$ of ethyl), 2.45 (t, 3H, and $-\mathrm{CH}_{3}$ of ethyl), 8.98 (s, $1 \mathrm{H}$, and $-\mathrm{SH}$ ), and 7.29-8.45 (complex, $\mathrm{m}$, and $4 \mathrm{H}$ aryl protons); ${ }^{13} \mathrm{C}$ NMR: $\delta 170.6,136.5,130.2,124.3,116.4,26.9$, and $22.8 \mathrm{ppm} ; \mathrm{MS}(\mathrm{CI}): \mathrm{m} / \mathrm{z} 193\left[\mathrm{M}^{\circ+}+1\right]$.

(1-Benzyl-1H-benzimidazol-2-yl)methanethiol, 2c. M.P. 134$38^{\circ} \mathrm{C}$ (Lit. ${ }^{(7)}$ m.p. $136-39^{\circ} \mathrm{C}$ ); IR (KBr): $2229-2258 \mathrm{~cm}^{-1}$ (-SH); ${ }^{1} \mathrm{H}$ NMR (400 MHz, DMSO-d 6 /TMS): $\delta 3.60$ (s, 2H, and $-\mathrm{NCH}_{2}$ of benzyl), $8.63(\mathrm{~s}, 1 \mathrm{H}$, and $-\mathrm{SH})$, and 7.28-8.48 (complex, $\mathrm{m}, 9 \mathrm{H}$, and 5 aromatic benzyl $+4 \mathrm{H}$ aryl protons); ${ }^{13}$ C NMR: $\delta 170.4,137.8,135.3,134.5,126.4,123.4,118.4$, and $44.9 \mathrm{ppm}$; MS (CI): m/z $255\left[\mathrm{M}^{\bullet+}+1\right]$.

\section{Conclusion}

In conclusion, we have developed simple and green synthesis of N-alkyl-2-thiomethyl benzimidazole under different conditions.

\section{Conflict of Interests}

The authors declare that there is no conflict of interests regarding the publication of this paper.

\section{Acknowledgment}

The authors are indebted to the authorities of Jawaharlal Nehru Technological University Hyderabad for providing facilities.

\section{References}

[1] A. Spasov, I. N. Yozhitsa, L. I. Bugaeva, and V. A. Anisimova, "Benzimidazole derivatives: spectrum of pharmacological activity and toxicological properties," Pharma Chemica Journal, vol. 33, pp. 232-243, 1999.

[2] P. N. Preston, The Chemistry of Heterocyclic Compounds, Benzimidazoles and Congeneric Tricyclic Compounds, Part-2, vol. 10, John Wiley \& Sons, New York, NY, USA, 1980.

[3] D. A. Horton, G. T. Bourne, and M. L. Smythe, "The combinatorial synthesis of bicyclic privileged structures or privileged substructures," Chemical Reviews, vol. 103, no. 3, pp. 893-930, 2003.
[4] P. N. Preston, "Synthesis, reactions, and spectroscopic properties of benzimidazoles," Chemical Reviews, vol. 74, no. 3, pp. 279-314, 1974.

[5] X. Han, H. Ma, and Y. Wang, "p-TsOH catalyzed synthesis of 2-arylsubstituted benzimidazoles," Arkivoc, vol. 2007, no. 13, pp. 150-154, 2007.

[6] M. T. Migawa, J.-L. Girardet, J. A. Walker II et al., "Design, synthesis, and antiviral activity of $\alpha$-nucleosides: $\mathrm{D}$ - and L-isomers of lyxofuranosyl- and (5-deoxylyxofuranosyl)benzimidazoles," Journal of Medicinal Chemistry, vol. 41, no. 8, pp. 1242-1251, 1998.

[7] A. R. Porcari, R. V. Devivar, L. S. Kucera, J. C. Drach, and L. B. Townsend, "Design, synthesis, and antiviral evaluations of 1-(substituted benzyl)- 2-substituted-5,6dichlorobenzimidazoles as nonnucleoside analogues of 2,5,6trichloro-1-( $\beta$-D-ribofuranosyl)benzimidazole," Journal of Medicinal Chemistry, vol. 41, no. 8, pp. 1252-1262, 1998.

[8] L. Casella, M. Gullotti, E. Suardi, M. Sisti, R. Pagliarin, and P. Zanello, "Blue copper models. Synthesis and characterization of copper(II) enethiolate complexes derived from (1R)-3hydroxymethylenebornane-2-thione and 2-aminothia-alkyl-1methylbenzimidazoles (donor set $\mathrm{N}_{2} \mathrm{SS}^{*}$ ) or diamines (donor set $\mathrm{N}_{2} \mathrm{~S}_{2}$ )," Journal of the Chemical Society, Dalton Transactions, no. 9, pp. 2843-2851, 1990.

[9] J. Rall, M. Wanner, M. Albrecht, F. M. Hornung, and W. Kaim, "Sensitive valence tautomer equilibrium of paramagnetic complexes $\left[(\mathrm{L}) \mathrm{Cu}^{n+}\left(\mathrm{Q}^{n-}\right)\right](n=1$ or $2 ; \mathrm{Q}=$ Quinones) related to amine oxidase enzymes," Chemistry, vol. 5, no. 10, pp. 28022809, 1999.

[10] J. Y. Kato, Y. Ito, R. Iluin, H. Aoyama, and T. Yokomastu, "Novel strategy for synthesis of substituted benzimidazole[1,2a] quinolines," Organic Letters, vol. 15, pp. 3794-3797, 2013.

[11] R. D. Haugwitz, B. V. Maurer, and V. L. Narayanan, "Synthesis and anthelmintic activity of some sulfonylbenzimidazoles," Journal of Medicinal Chemistry, vol. 15, no. 8, pp. 856-858, 1972.

[12] A. A. Zubenko, L. N. Fetisov, L. D. Popov, and E. Vihzila, "Preparation of pyrido[1,2-a]benzimidazole derivatives having antibacterial activity and process for their preparation," Russian Patent no. 2394824, Chemical Abstract 151859, 2008.

[13] S. S. Rao, P. K. Dubey, and Y. B. Kumari, "A Green and Simple synthesis of N-substituted-2-mercapto benzimidazoles," Indian Journal of Chemistry, vol. 52, pp. 1210-1213, 2013.

[14] S. S. Rao, Ch. V. R. Reddy, and P. K. Dubey, "A facile and green synthesis of N-substituted-2-chlorobenzimidazoles," Der Pharma Chemica, vol. 5, pp. 69-72, 2013. 

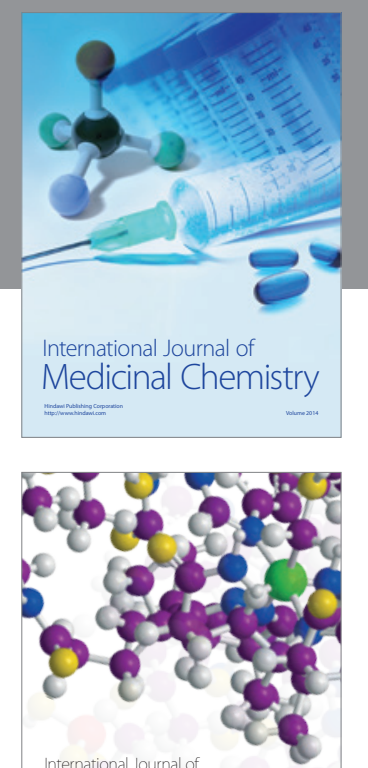

\section{Carbohydrate} Chemistry

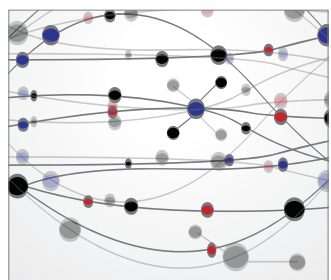

The Scientific World Journal
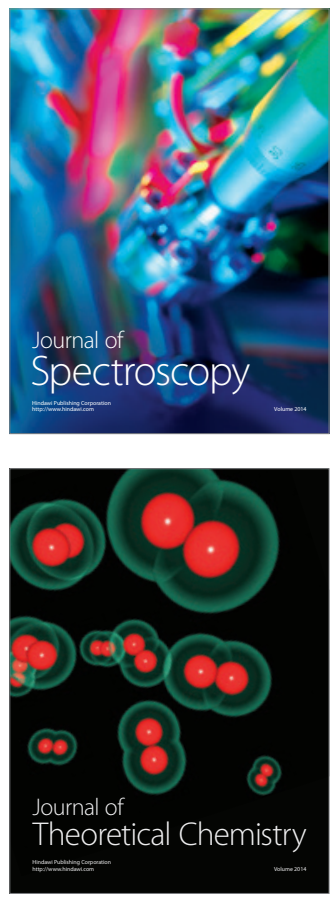
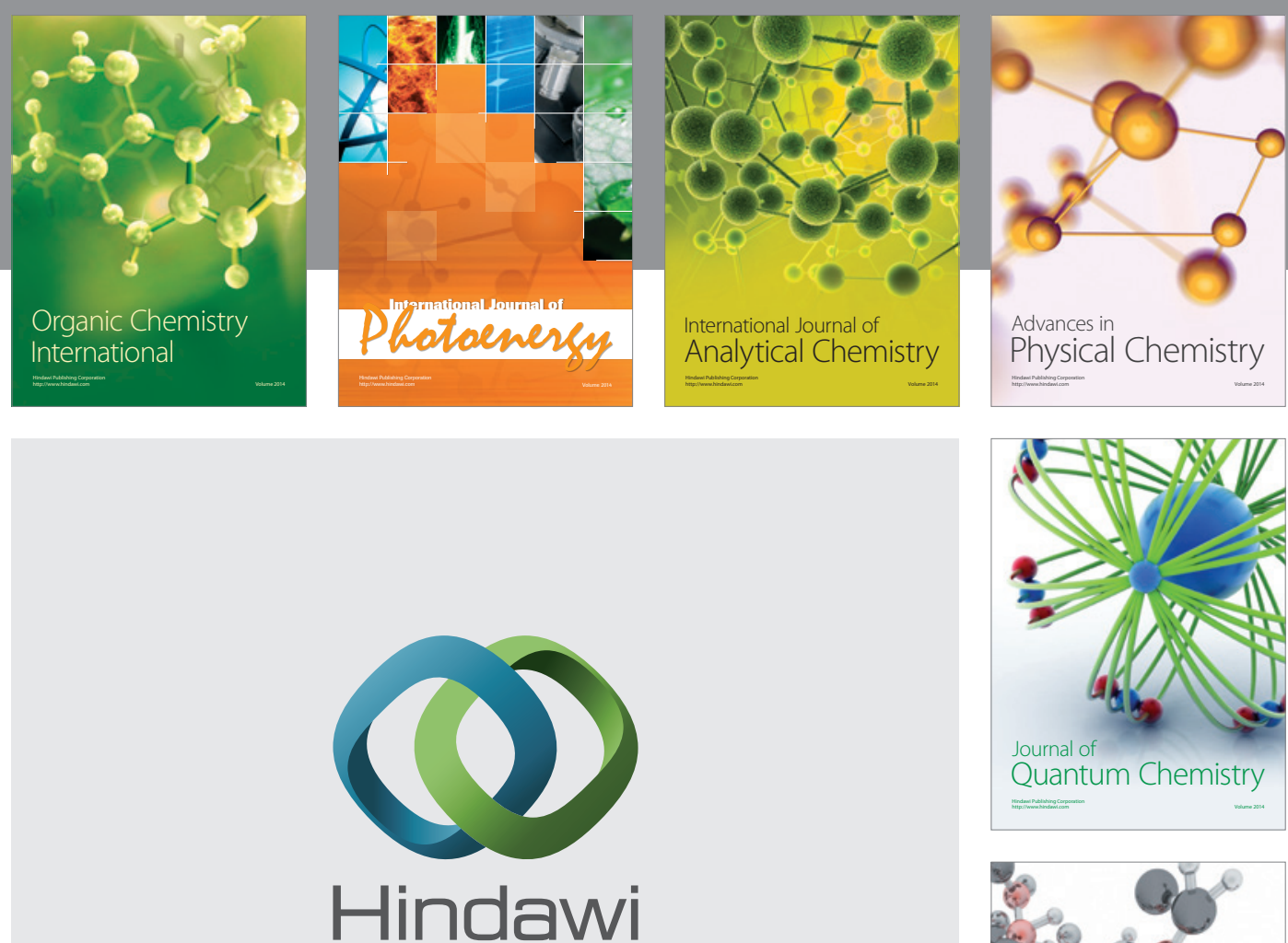

Submit your manuscripts at

http://www.hindawi.com

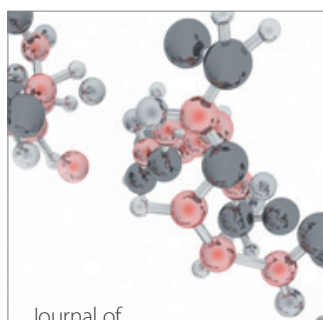

Analytical Methods

in Chemistry

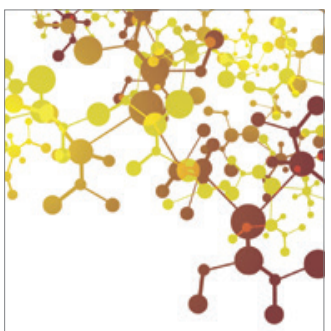

Journal of

Applied Chemistry

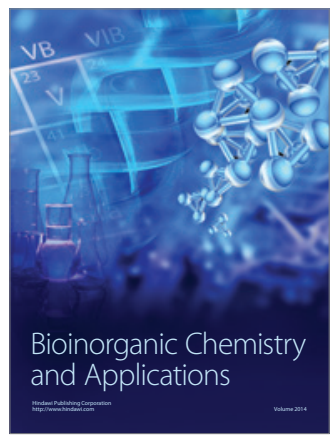

Inorganic Chemistry
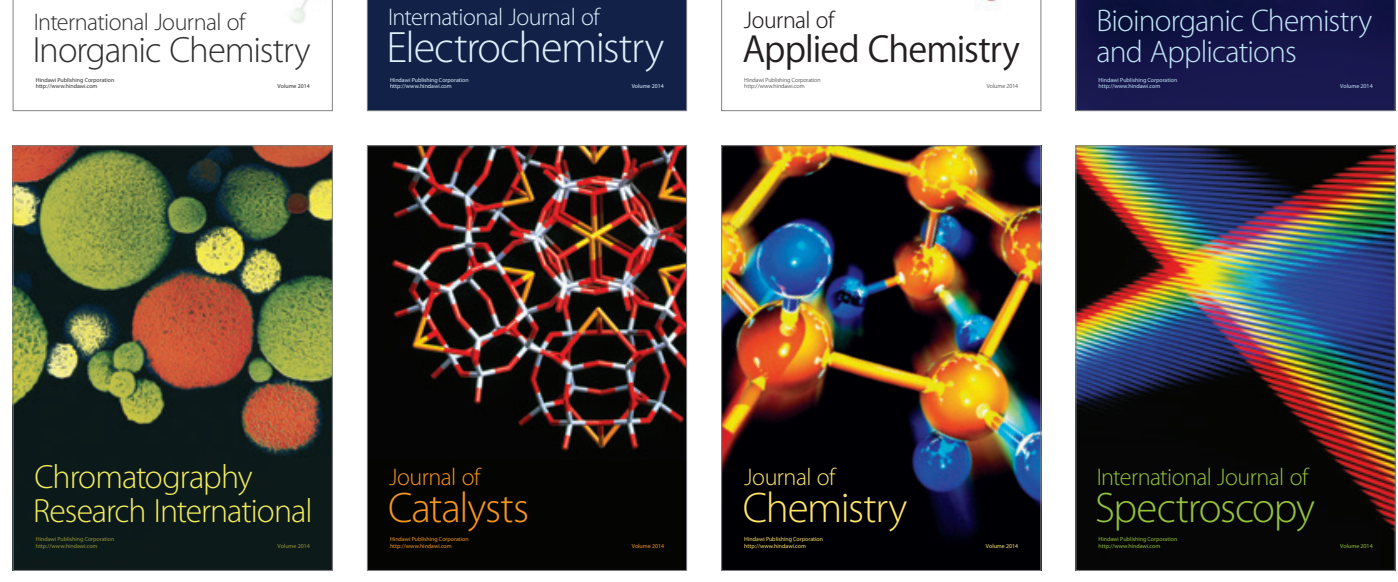